\title{
Dietary pattern, dietary total antioxidant capacity, and dyslipidemia in Korean adults
}

Seong-Ah Kim ${ }^{1,2}$, Hyojee Joung ${ }^{2,3}$ and Sangah Shin ${ }^{1 *}$ (D)

\begin{abstract}
Background: Abnormal diet is considered to be an important risk factor for dyslipidemia. However, so far, most studies have focused on the association between single factors only, such as specific nutrients, foods, or dietary patterns, and dyslipidemia risk. This study aimed to examine the association of the joint interaction between dietary pattern and dietary total antioxidant capacity (TAC) with dyslipidemia.

Methods: We performed a dietary pattern analysis and calculated the dietary TAC based on 24-h dietary recall (DR) data from Korea National Health and Nutrition Examination Survey (KNHANES) 2007-2012, which is representative population-based cross-sectional survey in Korea. A total of 29,624 participants aged over 19 years were included for the analysis. The number of people with hypercholesterolemia, hypertriglyceridemia, and hypoHDL-cholesterolemia was 3703,3513 , and 9802 , respectively. We examined the association between the joint classifications of dietary pattern score tertiles and dietary TAC level tertiles and dyslipidemia.

Results: Our results demonstrated that the "Rice \& Kimchi" pattern was associated with low prevalence of hypercholesterolemia, and high prevalence of hypertriglyceridemia and hypoHDL-cholesterolemia; whereas the pattern of both "Oil, sweets, fish \& other vegetables" and "Grain, bean, nuts, vegetables \& fruits" were associated with low prevalence of hypertriglyceridemia. Also we demonstrated that for all dietary patterns except for the "Grain, bean, nuts, vegetables \& fruits", dietary TAC was inversely associated with hypertriglyceridemia.

Conclusion: This study provides basic data for the lipid-lowering effect of dietary TAC and its interaction with dietary patterns. Further study will be needed to investigate the association between dietary TAC and dietary patterns with other diseases like metabolic syndrome, cardiovascular disease, or cancer.
\end{abstract}

Keywords: Dyslipidemia, Hypercholesterolemia, Hypertriglyceridemia, hypoHDL-cholesterolemia, Dietary pattern, Dietary total antioxidant capacity, KNHANES

\section{Background}

Numerous epidemiological studies have demonstrated that dyslipidemia is a major cause of cardiovascular disease [1,2]. Dyslipidemia is a condition characterized by abnormal lipid status (such as triglycerides [TG], cholesterol and/or phospholipids) in the blood. It comprises of elevated blood concentrations of the triad; low density lipoprotein cholesterol (LDL-C), TG, and decreased highdensity lipoprotein cholesterol (HDL-C) [3]. Among these

\footnotetext{
* Correspondence: ivory8320@cau.ac.kr

'Department of Food and Nutrition, Chung-Ang University, Gyeonggi-do

17546, Korea

Full list of author information is available at the end of the article
}

three components of dyslipidemia, elevated TG and decreased HDL-C are considered as prominent problems in Korea. The prevalence of elevated TG among Koreans rapidly increased from $10.2 \%$ in 1998 to $16.8 \%$ in 2012 [4], while that of decreased HDL-C was $26.2 \%$ in 2010 [5]. These two risk factors, elevated TG and decreased HDL$\mathrm{C}$, are commonly observed in Asian population. Recent pooled study of dyslipidemia showed that the prevalence of decreased HDL-C was $33.1 \%$ in Asian versus 27.0\% in non-Asian population [6]. Various studies pointed to the fact that diet may be a possible cause of such clear difference in dyslipidemia prevalence among populations $[2,7]$.

(C) The Author(s). 2019 Open Access This article is distributed under the terms of the Creative Commons Attribution 4.0 International License (http://creativecommons.org/licenses/by/4.0/), which permits unrestricted use, distribution, and reproduction in any medium, provided you give appropriate credit to the original author(s) and the source, provide a link to the Creative Commons license, and indicate if changes were made. The Creative Commons Public Domain Dedication waiver (http://creativecommons.org/publicdomain/zero/1.0/) applies to the data made available in this article, unless otherwise stated. 
Among the known risk factors of dyslipidemia, including genetic factors, hormonal abnormalities, and lifestyle factors [8], diet is considered to be one of the most important risk factors, which plays a key role in the development of dyslipidemia [9]. There are numerous evidences demonstrating the association between diet and blood lipid levels. Several studies indicated that dietary fat and cholesterol intake is associated with blood lipid levels [10, 11], while vegetables and fruits consumption is inversely associated with blood lipid levels $[12,13]$. However, few studies have researched the association between overall dietary pattern and the risk of dyslipidemia.

Recently, a growing body of research has addressed the importance of phytochemicals in decreasing the risk of chronic disease. This is because phytochemicals in plants, such as flavonoids and other phenolic compounds, have antioxidant capacity which may be able to protect cells from oxidative damage caused by free radicals [14]. Oxidative stress is known to cause oxidative damage to proteins and DNA, resulting in an increased risk of cancer and cardiovascular disease [15]. Among many kinds of phytochemicals, flavonoids have been suggested to reduce the risk of several age-related chronic diseases, by protecting LDL and very low-density lipoproteins (VLDL) from oxidation $[16,17]$. Antioxidant vitamins including vitamin A, C, E, and carotenoids also have beneficial health effects, by protecting LDL against oxidation and enhancing tumor surveillance through the immune system $[18,19]$. However, many antioxidant compounds generally coexist in foods, therefore, it may not be appropriate to examine the effect of any single antioxidant on human health. The concept of dietary total antioxidant capacity (TAC) was then introduced, considering the synergistic interaction between antioxidants and their differential ability against oxidation [20]. TAC is the cumulative ability of all antioxidants in food and characterizes the sum of all antioxidant properties of nutrients or compounds [21]. This concept can account for the additive and synergistic interaction of dietary antioxidants rather than individual effect of single antioxidants [21]. Dietary TAC has shown beneficial effects on degenerative diseases such as cancer, cardiovascular disease, and type 2 diabetes [22-24]. However, there is insufficient evidence about the association between dietary TAC and risk of dyslipidemia.

Furthermore, among various diet-related factors influencing dyslipidemia risk, most studies have focused on the association between single factors only, including specific nutrients, foods, or dietary patterns, and dyslipidemia risk. However, since an intricate interaction exists between each diet-related factors, the study examining the synergistic effects of those factors, needed to be conducted.

In recent nutritional epidemiological studies, the dietary pattern approach has emerged and widely used to examine complicated interactional and synergistic effects of nutrients and foods, on disease [25, 26]. Dietary patterns conceptually indicate a broader picture of the overall diet; therefore, examining the dietary patterns may be more predictive of disease risk than individual nutrients or foods [25]. In particular, because antioxidants are found in a wide variety of foods, the application of the dietary pattern method is more integrated than the analysis of single food or nutrient.

Therefore, in the present study, we performed the dietary pattern analysis to identify major dietary patterns in Korean population, to compare TAC levels according to dietary patterns; and finally, to examine the association of the joint interaction between dietary pattern and TAC with dyslipidemia.

\section{Methods \\ Study population}

Study population was participants in the fourth and fifth Korea National Health and Nutrition Examination Survey (KNHANES IV and KNHANES V) (2007-2012). KNHANES is a cross-sectional, nationally representative survey in South Korea carried out by the Korea Centers for Disease Control and Prevention every three years. KNHANES consists of a health examination survey, health behavioral survey, and nutritional survey. Among 33,843 adults aged over 19 years who had participated in all three surveys, we excluded people with implausible energy intake $(<500 \mathrm{kcal} /$ day or $\geq 5000 \mathrm{kcal} /$ day $)$ and insufficient information on blood samples, especially those who had missing data for total cholesterol, HDL-C, and TG. A total of 29,624 participants were finally selected for the analysis. The present study was conducted according to the guidelines laid down in the Declaration of Helsinki. All procedures for the Korea National Health and Nutrition Examination Survey were approved by the Korea Centers for Disease Control and Prevention Institutional Review Board (IRB No: 2007-02CON-04-P, 2008-04EXP-01-C, 2009-01CON-03-2C, 2010-02CON21-C, 2011-02CON-06-C, and 2012-01EXP-01-2C), and all participants provided written informed consent.

\section{Anthropometric measurement and blood test}

Participants' height and body weight, measured during the health examination survey, were used to calculate the body mass index (BMI, $\mathrm{kg} / \mathrm{m}^{2}$ ) for diagnosing obesity: underweight $\left(B M I<18.5 \mathrm{~kg} / \mathrm{m}^{2}\right)$, normal $(B M I \geq 18.5 \mathrm{~kg} /$ $\left.\mathrm{m}^{2},<23 \mathrm{~kg} / \mathrm{m}^{2}\right)$, overweight $\left(B M I \geq 23 \mathrm{~kg} / \mathrm{m}^{2},<25 \mathrm{~kg} / \mathrm{m}^{2}\right)$, and obese (BMI $\geq 25 \mathrm{~kg} / \mathrm{m}^{2}$ ) according to the International Obesity Task Force for adults in Asian and Pacific regions 
[27]. In the KNHANES, blood was collected from participants to test for blood lipid profile, total cholesterol, HDL-C, and TG. Dyslipidemia was defined as elevated cholesterol level (hypercholesterolemia: blood total cholesterol, $\geq 240 \mathrm{mg} / \mathrm{dL}$ ) or TG level (hypertriglyceridemia: blood TG, $\geq 200 \mathrm{mg} / \mathrm{dL}$ ), or lower HDL-C level (hypoHDL-cholesterolemia: blood HDL-C, < $40 \mathrm{mg} / \mathrm{dL}$ in men and $<50 \mathrm{mg} / \mathrm{dL}$ in women) [28].

\section{Assessment of other variables}

Sociodemographic variables such as age, sex, household income, and education; and lifestyle variables such as regular alcohol consumption, current smoking status, and physical activity were obtained through structured questionnaires. Household income was divided into four categories: low (first quartile), middle-low (second quartile), middle-high (third quartile), and high (fourth quartile). Also, educational level was divided into four categories: elementary school and lower, middle school, high school, and college and higher. Regular alcohol consumption was divided into two categories: 'yes' (drank more than once a month over the past year) and 'no'. Current smoking status was divided into two categories: 'yes' (smoked > 100 cigarettes over lifetime and still smoking) and 'no'. Physical activity was also divided into two categories: 'active' (performed moderateintensity physical activity which requires a moderate amount of effort and causes slightly rapid breathing for $\geq 30$ min once for $\geq 5$ days a week) and 'inactive' $[4,29]$.

\section{Assessment of dietary total antioxidant capacity}

The dietary intake was assessed using a one-day 24-h dietary recall (DR) method. Nutrients intake was calculated based on KNHANES nutrients database. We additionally estimated participants' dietary TAC using the TAC database developed previously [30]. In brief, the TAC database was developed for 42 dietary antioxidants (i.e., vitamins $\mathrm{C}$ and $\mathrm{E}$, carotenoids, and flavonoids), expressed as vitamin $\mathrm{C}$ equivalents (VCE) for foods commonly consumed in Korea. Daily TAC (mg VCE) from individual food item was determined by multiplying the daily consumption of the item (g) by the TAC of each food (mg VCE/100 g) in the TAC database. Daily TAC from diet was the sum of the daily TAC from all the food items reported in the 24-h DR.

\section{Dietary pattern analysis}

In total, 838 foods were reported in this study, and they were categorized into 24 food groups based on the Korean Nutrition Database and previous studies on the dietary patterns in Korea [31, 32] (Additional file 1: Table S1). Since rice is the staple food of Koreans, it was separated solely from the grain group. Similarly, since Kimchi is a most typically and frequently consumed
Korean food, it was also separated from vegetables and seasoning group. Kimchi is representative Korean fermented food known for its unique spicy taste and its health benefit related to antibacterial, anti-inflammatory, and anticancer potential [33-37], and recently introduced and consumed in many countries around the world. Meat was grouped as 'red meat and its products' and 'white meat and its product', on the basis of the nutrients content and the association of the food group with chronic diseases. Also, vegetable was categorized into 'green and yellow vegetables' and 'light-colored vegetables' since green and yellow vegetables generally contain more antioxidant compounds than light-colored vegetables.

The average energy intake from the 24 food groups was calculated individually. We conducted an explanatory factor analysis to identify the major dietary pattern based on the percentage of the total daily energy intake from the 24 food groups. In order to determine the number of factors, we considered eigenvalues (>1.20) and the scree plot (Additional file 2: Figure S1). The derived patterns were named from foods loaded most positively on the pattern. Participants had their own factor score for identified patterns, and they were categorized into tertiles for every emerged pattern by subject's factor score.

\section{Statistical analysis}

All statistical analyses were performed in SAS version 9.4 (SAS Institute Inc., Cary, NC, USA). We conducted the factor analysis using the FACTOR PROCEDURE in SAS 9.4. The factors were rotated by an orthogonal transformation using the Varimax rotation function in SAS to achieve a simpler structure and greater interpretability. The participants were divided into three groups according to each four dietary pattern scores tertiles. Differences across tertile groups of the dietary pattern scores were determined using chi-square test for categorical variables and generalized linear model for continuous variables. The assumption of generalized linear model that the dependent variable is independently distributed was checked by the plots and satisfied in all models. Multivariable-adjusted logistic regression analysis was conducted to compare the odds ratios (OR) and 95\% confidence intervals (CIs) for dyslipidemia among tertiles of each dietary pattern score and the nine combination groups (joint classifications for dietary pattern score tertiles and dietary TAC level tertiles). Logistic regression models were adjusted for sex, age, obesity level, household income, regular alcohol consumption, smoking status, physical activity, and energy intake. In general, because the correlation between educational level and household income level was high, only the household income level was selected as adjustment variable. Sensitivity analyses were conducted not only 
including education level as adjustment variable in the model but also excluding household income level after adjusted for education level. $\mathrm{P}$ for trend values were tested by assigning the median of each dietary pattern score as a continuous variable in the logistic regression model and using the CONTRAST statement in the logistic regression model to determine the linear trend for dyslipidemia according to tertiles of four dietary pattern and joint classifications for dietary pattern score tertiles and dietary TAC level tertiles, respectively. In the complex sampling design data, the missing values of the covariates are weighted in the relevant strata, so nonresponder information should be reflected in the analysis without missing the information. We treated all missing values as 'valid values' in all the analyses. Statistical significance was defined as $P<0.05$.

\section{Results}

Four dietary patterns were identified from the factor analysis (Table 1), and were named after food or food groups with high factor loading values. These four dietary patterns accounted for $26 \%$ of the total variance: 9.0 , 6.1 , 5.5, and 5.1\%, respectively. The "Rice \& Kimchi" pattern featured a high consumption of rice and Kimchi whereas it had a negative loading for noodles and dumpling, bread and snack, fruits, eggs, milk, and dairy products; and beverage. The "Oil, sweets, fish \& other vegetables" pattern had high positive factor loading for oil, sweets, seasoning, fish, and shellfish; as well as eggs and other vegetables (non-green and yellow vegetables). The "Red meat \& alcohol" pattern was characterized by high consumption of red meat and alcohol, while the "Grain, bean, nuts, vegetables, \& fruits" pattern showed high positive factor loading for other grains, fruits, bean, Tofu, and soymilk; nuts and seeds; and vegetables including green and yellow vegetables.

Table 2 shows the general characteristics of study participants according to the four dietary pattern scores. Participants with higher scores of the "Rice \& Kimchi" pattern were more likely to be older whereas participants with higher scores of "Oil, sweets, fish, \& other vegetables" pattern and "Red meat \& alcohol" pattern were more likely to be younger (all $P<0.001$ ). The highest pattern score group for "Grain, bean, nuts, vegetables, \& fruits" was associated with the highest proportion of women. The "Grain, bean, nuts, vegetables, \& fruits" pattern score was inversely related with regular alcohol consumption and current smoking (all $P<0.001$ ).

Nutrients intake and dietary antioxidant capacity of participants, according to the four dietary pattern scores are shown in Table 3. Because the nutrient intake and dietary antioxidant capacity were not normally distributed, the medians (25th -75 th percentiles) for each nutrient and antioxidant were presented. The "Rice \&
Kimchi" pattern score was inversely associated with total energy, vitamin $\mathrm{C}$, vitamin $\mathrm{E}$, carotenoids, flavonoids, and dietary TAC (all $P<0.001$ ). On the other hand, "Oil, sweets, fish, \& other vegetables" pattern and "Red meat \& alcohol" pattern were positively associated with total energy, vitamin $\mathrm{C}$, vitamin $\mathrm{E}$, carotenoids, flavonoids, and dietary TAC (all $P<0.05$ ). The difference of dietary TAC intake between tertiles of pattern score was largest in the "Grain, bean, nuts, vegetables, \& fruits" pattern (the lowest tertile: median [25th - 75th percentiles], 138.7 [73.4-267.2] $\mathrm{mg} /$ day; the highest tertile: 358.6 [198.0-677.2] mg/day, $P<0.001$ ).

Finally, we examined dyslipidemia risk according to the four dietary pattern scores (Table 4) and the joint classifications of the dietary pattern scores and dietary TAC (Table 5). After adjustment for sex, age, obesity level, household income, regular alcohol consumption, smoking status, physical activity, and energy intake, the OR for risks of hypercholesterolemia, hypertriglyceridemia, and hypoHDL-cholesterolemia from the lowest to the highest tertiles of the "Rice \& Kimchi" pattern scores were 0.79 [95\% CI 0.72-0.87], 1.33 [95\% CI 1.201.47], and 1.21 [95\% CI 1.13-1.30], respectively. It seemed that the "Rice \& Kimchi" pattern had the opposite association with hypertriglyceridemia compared to the "Oil, sweets, fish, \& other vegetables" pattern and the "Grain, bean, nuts, vegetables, \& fruits" pattern. While the highest tertile of the "Rice \& Kimchi" pattern scores showed a $33 \%$ higher likelihood of having hypertriglyceridemia compared to the lowest tertile, the highest tertile of the "Oil, sweets, fish \& other vegetables" pattern scores and the "Grain, bean, nuts, vegetables, \& fruits" pattern scores showed 27 and 12\% lower likelihood of having hypertriglyceridemia compared to the lowest tertile, respectively. Also, the "Rice \& Kimchi" pattern have the opposite association with hypoHDLcholesterolemia risk compared to the "Red meat \& alcohol" pattern. The highest tertile of the "Red meat \& alcohol" pattern scores showed an 12\% lower likelihood of having hypoHDL-cholesterolemia compared to the lowest tertile. The results of sensitivity analyses including education level as adjustment variable and excluding household income level after adjusted for education level were similar to those in Table 4 (Data not shown).

The results of the association between the joint classifications of the dietary pattern scores and dietary TAC, and dyslipidemia risk are presented in Table 5. Among the dyslipidemia components, hypertriglyceridemia was significantly associated with the joint classification of the dietary pattern scores and TAC in all dietary patterns except for the "Grain, bean, nuts, vegetables, \& fruits". In the highest tertile of the "Rice \& Kimchi" pattern scores and the "Red meat \& alcohol" pattern scores, the lowest tertile of TAC showed 35\% and 24\% higher likelihood of 
Table 1 Factor loading matrix of food groups for the four dietary patterns identified from the 24-h dietary recall

\begin{tabular}{|c|c|c|c|c|}
\hline Food or food groups & $\begin{array}{l}\text { Pattern } 1 \text { Rice } \\
\text { \& Kimchi }\end{array}$ & $\begin{array}{l}\text { Pattern } 2 \text { Oil, sweets, } \\
\text { seasoning, fish \& other } \\
\text { vegetables }\end{array}$ & $\begin{array}{l}\text { Pattern } 3 \text { Red } \\
\text { meat \& alcohol }\end{array}$ & $\begin{array}{l}\text { Pattern } 4 \text { Grain, bean, } \\
\text { nuts, vegetables \& fruits }\end{array}$ \\
\hline Rice & 0.74 & -0.25 & -0.39 & \\
\hline Other grains & & & & 0.32 \\
\hline Noodles and dumpling & -0.29 & & & -0.39 \\
\hline Bread and snack & -0.58 & & & \\
\hline \multicolumn{5}{|l|}{ Potatoes and corn } \\
\hline Sweets & & 0.53 & & \\
\hline Seasoning & & 0.34 & 0.33 & 0.28 \\
\hline Bean, Tofu, and soymilk & & & & 0.31 \\
\hline Nuts and seeds & & & & 0.36 \\
\hline Green and yellow vegetables & & & & 0.40 \\
\hline Light-colored vegetables & & 0.41 & & 0.33 \\
\hline Kimchi & 0.34 & & & \\
\hline Mushroom & & & & 0.25 \\
\hline Fruits & -0.27 & & & 0.30 \\
\hline Red meats and its product & & & 0.61 & \\
\hline \multicolumn{5}{|l|}{ White meats and its product } \\
\hline Eggs & -0.25 & 0.26 & & -0.28 \\
\hline Fish and Shellfish & & 0.39 & & \\
\hline Seaweeds & & & -0.33 & \\
\hline Milk and dairy products & -0.51 & & & \\
\hline Oil & & 0.74 & & \\
\hline Beverage & -0.27 & & & \\
\hline Alcohol & & & 0.65 & \\
\hline Coffee and Tea & & & & -0.33 \\
\hline
\end{tabular}

* For simplicity, factor loading values less than 0.25 are not listed in the matrix.* Four dietary patterns were derived by principal component analysis after entering the 24 food groups into the FACTOR PROCEDURE. The factors were rotated by orthogonal transformations (Varimax rotation function in SAS), and the number of factors was determined based on eigenvalues $(>1.20)$

having hypertriglyceridemia compared to the reference group, respectively. On the other hand, the highest tertile of TAC in the same group showed no significant risk of hypertriglyceridemia. Likewise, in the "Oil, sweets, fish, \& other vegetables" pattern, within similar levels of dietary pattern scores, the risk of hypertriglyceridemia was significantly decreased according to the TAC level ( $\mathrm{p}$ for trend $=$ 0.020, 0.042, and 0.007 for the "Rice \& Kimchi" pattern, the "Oil, sweets, fish, \& other vegetables" pattern, and the "Red meat \& alcohol" pattern, respectively).

\section{Discussion}

In the present study, we derived four distinct dietary patterns, which are, the "Rice \& Kimchi", the "Oil, sweets, fish, \& other vegetables", the "Red meat \& alcohol", and the "Grain, bean, nuts, vegetables, \& fruits" patterns, among Korean adults. The major derived patterns were similar to those observed in several other studies [31, 32].
To the knowledge of the authors, this is the first study to identify association between dietary patterns and dietary TAC with dyslipidemia. We found that the "Rice \& Kimchi" pattern was associated with low prevalence of hypercholesterolemia and high prevalence of hypertriglyceridemia and hypoHDL-cholesterolemia whereas the "Oil, sweets, fish, \& other vegetables" and "Grain, bean, nuts, vegetables, \& fruits" patterns were associated with low prevalence of hypertriglyceridemia. The "Red meat \& alcohol" pattern was associated with low prevalence of hypoHDL-cholesterolemia. Also, we demonstrated that dietary TAC was inversely associated with the risk of dyslipidemia with a similar pattern score. For all dietary patterns except for the "Grain, bean, nuts, vegetables, \& fruits", dietary TAC was inversely associated with hypertriglyceridemia.

With regard to dyslipidemia, studies on the association between dietary pattern and risk of dyslipidemia were lacking. With blood HDL-C, an earlier 


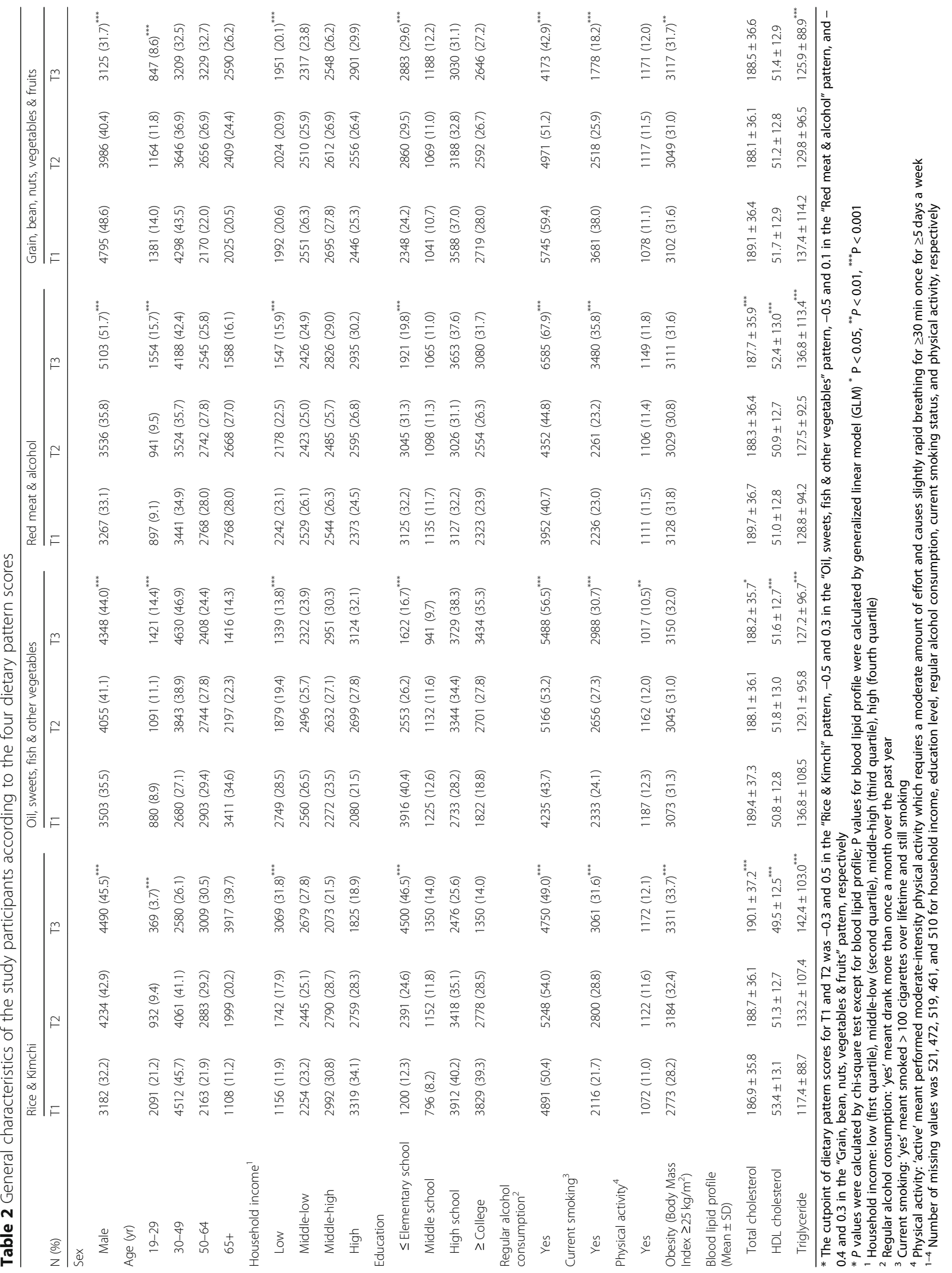


Table 3 Nutrients intake and dietary antioxidant capacity of participants according to the four dietary pattern scores

\begin{tabular}{|c|c|c|c|c|}
\hline \multirow[b]{2}{*}{ Median (25th - 75th percentiles) } & \multicolumn{4}{|l|}{ Tertile of pattern scores } \\
\hline & $\mathrm{T} 1$ & $\mathrm{~T} 2$ & $\mathrm{~T} 3$ & $p$-value \\
\hline \multicolumn{5}{|l|}{ Rice \& Kimchi } \\
\hline Energy (Kcal/d) & $1880.3(1444.7-2433.4)$ & $1852.7(1419.5-2368.7)$ & $1583.8(1235.4-2007.7)$ & $<0.001$ \\
\hline \multicolumn{5}{|l|}{ Dietary total antioxidant capacity } \\
\hline Vitamin C (mg VCE/d) & $77.9(35.1-173.0)$ & $71.5(36.8-142.0)$ & $49.0(24.7-92.3)$ & $<0.001$ \\
\hline Retinol (mg VCE/d) & $0.0(0.0-0.1)$ & $0.0(0.0-0.1)$ & $0.0(0.0-0.0)$ & $<0.001$ \\
\hline Vitamin E (mg VCE/d) & $4.3(2.8-6.4)$ & $3.9(2.6-5.9)$ & $3.0(1.8-4.6)$ & $<0.001$ \\
\hline Carotenoids (mg VCE/d) & $1.5(0.7-3.5)$ & $1.4(0.7-3.2)$ & $1.0(0.4-2.3)$ & $<0.001$ \\
\hline Flavonoids (mg VCE/d) & $165.3(71.1-371.9)$ & $163.0(79.5-319.4)$ & $104.2(49.8-212.5)$ & $<0.001$ \\
\hline TAC (mg VCE/d) & $273.2(133.0-576.3)$ & $260.6(137.1-482.8)$ & $169.7(89.3-318.5)$ & $<0.001$ \\
\hline \multicolumn{5}{|l|}{ Oil, sweets, fish, \& other vegetables } \\
\hline Energy (Kcal/d) & $1647.4(1272.3-2130.5)$ & $1778.6(1387.1-2265.7)$ & $1869.5(1419.9-2406.9)$ & $<0.001$ \\
\hline \multicolumn{5}{|l|}{ Dietary total antioxidant capacity } \\
\hline Vitamin C (mg VCE/d) & $57.9(23.3-141.8)$ & $62.6(32.3-125.1)$ & $70.4(38.3-128.8)$ & $<0.001$ \\
\hline Retinol (mg VCE/d) & $0.0(0.0-0.0)$ & $0.0(0.0-0.1)$ & $0.0(0.0-0.1)$ & $<0.001$ \\
\hline Vitamin E (mg VCE/d) & $2.9(1.8-4.5)$ & $3.6(2.4-5.3)$ & $4.8(3.2-6.9)$ & $<0.001$ \\
\hline Carotenoids (mg VCE/d) & $0.8(0.3-2.0)$ & $1.3(0.6-3.0)$ & $1.8(0.9-4.0)$ & $<0.001$ \\
\hline Flavonoids (mg VCE/d) & $129.9(51.6-317.4)$ & $142.3(67.4-296.6)$ & $147.6(76.8-277.5)$ & $<0.001$ \\
\hline TAC (mg VCE/d) & $210.9(92.5-484.8)$ & $230.0(120.8-446.6)$ & $241.5(136.8-426.5)$ & $<0.001$ \\
\hline \multicolumn{5}{|l|}{ Red meat \& alcohol } \\
\hline Energy (Kcal/d) & $1574.2(1229.1-1993.2)$ & $1716.7(1338.0-2180.3)$ & $2056.6(1570.3-2648.9)$ & $<0.001$ \\
\hline \multicolumn{5}{|l|}{ Dietary total antioxidant capacity } \\
\hline Vitamin C (mg VCE/d) & $61.7(27.0-141.3)$ & $65.3(31.7-134.3)$ & $64.9(35.3-121.4)$ & $<0.001$ \\
\hline Retinol (mg VCE/d) & $0.0(0.0-0.1)$ & $0.0(0.0-0.1)$ & $0.0(0.0-0.1)$ & $<0.001$ \\
\hline Vitamin E (mg VCE/d) & $3.5(2.2-5.3)$ & $3.6(2.3-5.5)$ & $4.1(2.7-6.1)$ & $<0.001$ \\
\hline Carotenoids (mg VCE/d) & $1.1(0.5-2.7)$ & $1.3(0.5-3.1)$ & $1.4(0.7-3.2)$ & $<0.001$ \\
\hline Flavonoids (mg VCE/d) & $132.6(54.3-307.0)$ & $143.1(64.4-306.2)$ & $145.9(75.6-277.8)$ & 0.019 \\
\hline TAC (mg VCE/d) & $220.0(100.0-470.1)$ & $233.3(118.2-464.3)$ & $234.1(129.9-417.4)$ & $<0.001$ \\
\hline \multicolumn{5}{|l|}{ Grain, bean, nuts, vegetables, \& fruits } \\
\hline Energy (Kcal/d) & $1789.6(1365.6-2357.2)$ & $1799.7(1386.4-2305.2)$ & $1706.0(1320.4-2177.9)$ & $<0.001$ \\
\hline \multicolumn{5}{|l|}{ Dietary total antioxidant capacity } \\
\hline Vitamin C (mg VCE/d) & $42.4(22.2-82.3)$ & $66.0(33.4-127.1)$ & $96.9(47.5-194.5)$ & $<0.001$ \\
\hline Retinol (mg VCE/d) & $0.0(0.0-0.1)$ & $0.0(0.0-0.1)$ & $0.0(0.0-0.1)$ & 0.632 \\
\hline Vitamin E (mg VCE/d) & $3.4(2.1-5.1)$ & $3.6(2.3-5.5)$ & $4.3(2.8-6.4)$ & $<0.001$ \\
\hline Carotenoids (mg VCE/d) & $0.9(0.4-1.8)$ & $1.2(0.6-2.8)$ & $2.0(0.9-4.7)$ & $<0.001$ \\
\hline Flavonoids (mg VCE/d) & $82.6(37.6-171.0)$ & $143.2(70.1-280.5)$ & $225.1(114.7-455.6)$ & $<0.001$ \\
\hline TAC (mg VCE/d) & $138.7(73.4-267.2)$ & $230.8(125.3-426.2)$ & $358.6(198.0-677.2)$ & $<0.001$ \\
\hline
\end{tabular}

* The cutpoint of dietary pattern scores for T1 and T2 was -0.3 and 0.5 in the "Rice $\&$ Kimchi" pattern, -0.5 and 0.3 in the "Oil, sweets, fish \& other vegetables" pattern, -0.5 and 0.1 in the "Red meat \& alcohol" pattern, and -0.4 and 0.3 in the "Grain, bean, nuts, vegetables \& fruits" pattern, respectively * $P$ values were calculated by generalized linear model (GLM) VCE vitamin C equivalents, TAC total antioxidant capacity

study showed that people in countries with highcarbohydrate and low-fat diet tend to have low blood HDL-C [38]. Several studies in Asian countries also demonstrated similar results $[39,40]$. In contrast to Western diets, typical Asian diets are rice-based, rich in plant foods, high in carbohydrate, and low in fat [40]. This might be the reason why hypoHDLcholesterolemia is more prevalent in Asian population than any other country [6]. Also fiber intake from grain, vegetables and fruits was associated with 


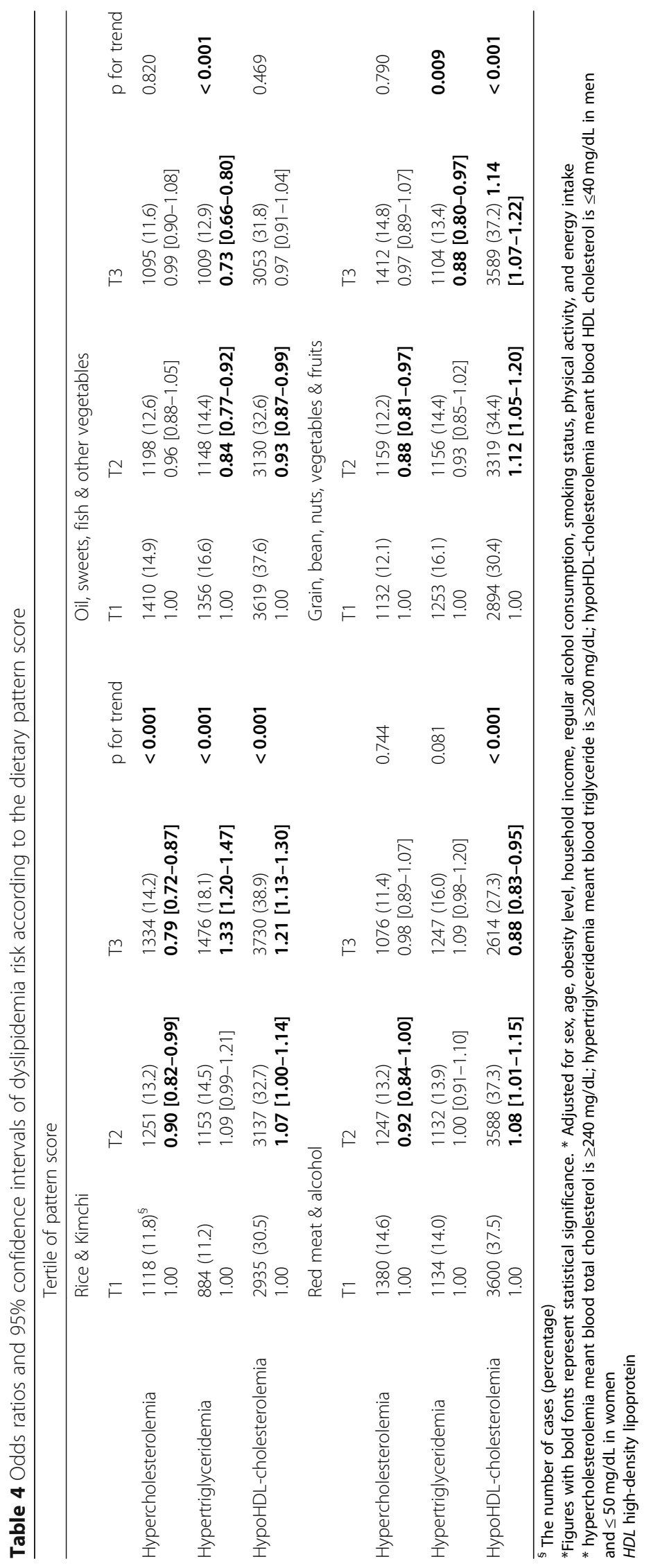


Table 5 Odds ratios and 95\% confidence intervals of dyslipidemia risk according to the joint classifications of the dietary pattern score and dietary total antioxidant capacity

\begin{tabular}{|c|c|c|c|c|c|c|c|}
\hline & & \multicolumn{6}{|c|}{ Tertile of pattern score } \\
\hline & & \multicolumn{3}{|l|}{ Rice \& Kimchi } & \multicolumn{3}{|c|}{ Oil, sweets, fish \& other vegetables } \\
\hline & & $\mathrm{T} 1$ & $\mathrm{~T} 2$ & T3 & $\mathrm{T} 1$ & $\mathrm{~T} 2$ & T3 \\
\hline & & \multicolumn{3}{|c|}{ Hypercholesterolemia } & \multicolumn{3}{|c|}{ Hypercholesterolemia } \\
\hline \multirow[t]{17}{*}{ Dietary TAC (mg VCE/d) } & $\mathrm{T} 1$ & 1.00 & $1.00[0.83-1.20]$ & $0.89[0.75-1.05]$ & 1.00 & $1.03[0.89-1.19]$ & $0.95[0.80-1.11]$ \\
\hline & $\mathrm{T} 2$ & $1.08[0.90-1.30]$ & $1.02[0.86-1.21]$ & $0.89[0.75-1.06]$ & $1.04[0.90-1.21]$ & $0.96[0.82-1.11]$ & $1.08[0.93-1.25]$ \\
\hline & T3 & $1.18[1.00-1.40]$ & $0.97[0.82-1.15]$ & $0.82[0.68-0.99]$ & $1.08[0.94-1.25]$ & $1.01[0.87-1.18]$ & $1.04[0.89-1.22]$ \\
\hline & $p$ for trend & 0.511 & & & 0.492 & & \\
\hline & & \multicolumn{3}{|c|}{ Hypertriglyceridemia } & \multicolumn{3}{|c|}{ Hypertriglyceridemia } \\
\hline & $\mathrm{T} 1$ & 1.00 & $1.13[0.93-1.36]$ & $1.35[1.13-1.60]$ & 1.00 & $0.82[0.71-0.96]$ & $0.73[0.62-0.86]$ \\
\hline & $\mathrm{T} 2$ & $0.93[0.76-1.13]$ & $0.92[0.77-1.11]$ & $1.24[1.03-1.48]$ & $0.89[0.76-1.04]$ & $0.80[0.69-0.93]$ & $0.62[0.53-0.73]$ \\
\hline & T3 & $0.93[0.78-1.12]$ & $1.09[0.91-1.30]$ & $1.19[0.98-1.45]$ & $0.89[0.77-1.03]$ & $0.73[0.63-0.85]$ & $0.69[0.58-0.81]$ \\
\hline & $\mathrm{p}$ for trend & \multicolumn{3}{|l|}{0.020} & \multicolumn{3}{|l|}{0.042} \\
\hline & & \multicolumn{3}{|c|}{ HypoHDL-cholesterolemia } & \multicolumn{3}{|c|}{ HypoHDL-cholesterolemia } \\
\hline & $\mathrm{T} 1$ & 1.00 & $1.05[0.93-1.19]$ & $1.20[1.07-1.34]$ & 1.00 & $0.93[0.83-1.03]$ & $0.95[0.85-1.06]$ \\
\hline & $\mathrm{T} 2$ & $1.01[0.90-1.14]$ & $1.00[0.89-1.13]$ & $1.19[1.06-1.34]$ & $0.99[0.88-1.11]$ & $0.92[0.82-1.02]$ & $0.94[0.84-1.04]$ \\
\hline & T3 & $0.99[0.88-1.11]$ & $1.14[1.02-1.28]$ & $1.27[1.11-1.45]$ & $0.99[0.89-1.11]$ & $0.93[0.83-1.04]$ & $1.02[0.91-1.14]$ \\
\hline & $\mathrm{p}$ for trend & \multicolumn{3}{|l|}{0.708} & & \multicolumn{2}{|l|}{0.714} \\
\hline & & \multicolumn{3}{|c|}{ Red meat \& alcohol } & \multicolumn{3}{|c|}{ Grain, bean, nuts, vegetables \& fruits } \\
\hline & & $\mathrm{T} 1$ & $\mathrm{~T} 2$ & T3 & $\mathrm{T} 1$ & $\mathrm{~T} 2$ & T3 \\
\hline & & \multicolumn{3}{|c|}{ Hypercholesterolemia } & \multicolumn{3}{|c|}{ Hypercholesterolemia } \\
\hline \multirow[t]{14}{*}{ Dietary TAC (mg VCE/d) } & $\mathrm{T} 1$ & 1.00 & $0.92[0.79-1.06]$ & $0.90[0.76-1.06]$ & 1.00 & $0.79[0.68-0.91]$ & $0.91[0.76-1.08]$ \\
\hline & $\mathrm{T} 2$ & $0.95[0.82-1.11]$ & $0.95[0.82-1.10]$ & $1.02[0.87-1.19]$ & $0.93[0.79-1.08]$ & $0.92[0.80-1.06]$ & $0.96[0.84-1.10]$ \\
\hline & T3 & $1.05[0.91-1.22]$ & $0.90[0.78-1.05]$ & $1.03[0.87-1.21]$ & $1.03[0.85-1.24]$ & $0.90[0.77-1.04]$ & $0.97[0.86-1.10]$ \\
\hline & $p$ for trend & 0.439 & & & 0.345 & & \\
\hline & & \multicolumn{3}{|c|}{ Hypertriglyceridemia } & \multicolumn{3}{|c|}{ Hypertriglyceridemia } \\
\hline & T1 & 1.00 & $1.20[1.03-1.40]$ & $1.24[1.06-1.46]$ & 1.00 & $0.86[0.74-1.00]$ & $0.84[0.69-1.01]$ \\
\hline & $\mathrm{T} 2$ & $0.97[0.82-1.15]$ & $0.99[0.84-1.16]$ & 1.04 [0.89-1.23] & $0.83[0.71-0.97]$ & $0.82[0.71-0.94]$ & $0.82[0.71-0.95]$ \\
\hline & T3 & $1.11[0.95-1.30]$ & $0.92[0.78-1.08]$ & $1.06[0.89-1.26]$ & $0.84[0.70-1.01]$ & 0.90 [0.77-1.04] & $0.80[0.70-0.91]$ \\
\hline & $\mathrm{p}$ for trend & \multicolumn{3}{|l|}{0.007} & \multicolumn{3}{|l|}{0.104} \\
\hline & & \multicolumn{3}{|c|}{ HypoHDL-cholesterolemia } & \multicolumn{3}{|c|}{ HypoHDL-cholesterolemia } \\
\hline & $\mathrm{T} 1$ & 1.00 & $1.12[1.01-1.25]$ & $0.81[0.72-0.91]$ & 1.00 & $1.13[1.02-1.25]$ & $1.23[1.08-1.40]$ \\
\hline & $\mathrm{T} 2$ & $0.97[0.87-1.08]$ & $1.01[0.91-1.13]$ & $0.90[0.80-1.00]$ & $0.96[0.86-1.07]$ & 1.07 [0.97-1.19] & $1.12[1.01-1.23]$ \\
\hline & T3 & $0.99[0.89-1.10]$ & $1.07[0.96-1.19]$ & $0.91[0.81-1.02]$ & $0.99[0.87-1.13]$ & $1.12[1.01-1.25]$ & $1.10[1.01-1.21]$ \\
\hline & $p$ for trend & \multicolumn{3}{|l|}{0.773} & \multicolumn{3}{|l|}{0.076} \\
\hline
\end{tabular}

*Figures with bold fonts represent statistical significance. * Adjusted for sex, age, obesity level, household income, regular alcohol consumption, smoking status and physical activity

* hypercholesterolemia meant blood total cholesterol is $\geq 240 \mathrm{mg} / \mathrm{dL}$; hypertriglyceridemia meant blood triglyceride is $\geq 200 \mathrm{mg} / \mathrm{dL}$; hypoHDL-cholesterolemia meant blood HDL cholesterol is $\leq 40 \mathrm{mg} / \mathrm{dL}$ in men and $\leq 50 \mathrm{mg} / \mathrm{dL}$ in women

TAC total antioxidant capacity, VCE vitamin C equivalent, $H D L$ high-density lipoprotein

lower blood HDL-C [41]. The results of the present study showing that the "Rice \& Kimchi" and "Grain, bean, nuts, vegetables, \& fruits" pattern was associated with high prevalence of hypoHDL-cholesterolemia were consistent with findings from a previous study [39-42].
With blood total cholesterol and LDL-C, high intakes of saturated fatty acids and cholesterol directly raise LDL-C concentrations, while the consumption of plant stanols/sterols, viscous (soluble) fiber and soy protein help lower LDLcholesterol concentrations [43]. Findings from several intervention studies showed that the reduction in dietary 
total fat, saturated fat, and cholesterol significantly decreased blood LDL-C [44, 45]. Some foods, such as whole grains, vegetables, and some fruits, contain viscous fiber that also helps to lower LDL-C. Previous study indicates that viscous (soluble) forms of dietary fiber can reduce LDL-C levels [43]. High intakes of soy protein can also lower LDL-C levels, especially when it is used to replace animal food products [43]. There is some evidence that the LDLlowering effect is dependent upon isoflavone content [46], but conclusive data are lacking. Also, low glycemic index (GI) diet was found to have the beneficial effect of lowering LDL-C and total cholesterol as compared with the high GI diet [47]. In this study, we found that the "Rice \& Kimchi" pattern was associated with low prevalence of hypercholesterolemia. This is consistent with previous findings that total fat is positively related to the blood total concentration of cholesterol while dietary fiber is inversely associated with the blood LDL-C. However, the "Grain, bean, nuts, vegetables, \& fruits" pattern was not linearly associated with hypercholesterolemia.

For blood TG, the evidence suggests that eicosapentaenoic (EPA) and docosahexaenoic (DHA) acids, both omega-3 fatty acids found in fish, lower blood TG $[48,49]$. Not only green vegetables but also total vegetable intakes significantly decreased blood TG level [50]. Nut consumption also improved blood TG levels among participants with higher blood TG levels [51]. These findings were supported by the results of the present study that the "Oil, sweets, fish, \& other vegetables" and "Grain, bean, nuts, vegetables, \& fruits" patterns were associated with low prevalence of hypertriglyceridemia.

In the present study, dietary TAC was inversely associated with dyslipidemia, especially hypertriglyceridemia. This might be attributed to the antioxidants in foods, which protects LDL against oxidation and enhances tumor surveillance though the immune system $[18,19]$. Previous studies reported that dietary TAC is inversely associated with the risk of cardiovascular disease [52], and cancer $[53,54]$. Our results suggest that dietary TAC may be an important predictor of dyslipidemia, like other wellknown diseases such as cardiovascular disease and cancer.

In this study, we uncovered the synergistic effects between dietary patterns and dietary TAC. We found that the prevalence of disease could vary according to the dietary TAC level even in people who share similar dietary pattern. Therefore, in planning a meal, it is necessary to consider not only qualitative quality such as dietary pattern and food composition but also quantitative quality such as dietary TAC.

The strength of this study is in its analytical methodology, which enabled us to figure out the relationship between the combined dietary patterns and dietary TAC, with dyslipidemia. Previous studies on dietary pattern and disease risk were limited because they solely focused on the dietary pattern and its association with disease. Second, this is the first study to identify the association between dietary patterns and dyslipidemia.

However, some limitations also need to be considered in the interpretation of results. First, because of the cross-sectional design of the KNHANES, we cannot confirm causation, but can make inferences about causal association. Second, there is a possibility that the oneday 24-h DR method may not reflect the subject's usual intake. Finally, the factor analysis approach involves several arbitrary but important decisions, including the consolidation of food items into food groups, the number of factors to extract, the method of rotation, and even the labelling of the components [55]. Therefore, the dietary pattern approach can be somewhat subjective, and the results may be difficult to replicate in other population. Nevertheless, dietary pattern approach is useful especially when many dietary factors have been demonstrated for disease (e.g. cardiovascular disease, metabolic syndrome, and dyslipidemia) because it goes beyond nutrients and foods, to examine the effects of overall diet [14].

\section{Conclusions}

This study provides basic data for the lipid-lowering effect of dietary TAC and its interaction with dietary pattern. Further study will be needed to investigate the association between dietary TAC and dietary pattern with other diseases such as metabolic syndrome, cardiovascular disease, or cancer.

\section{Additional file}

Additional file 1: Table S1. Food grouping used in the dietary pattern analysis. (DOCX $14 \mathrm{~kb}$ )

Additional file 2: Figure S1. Scree plot of eigenvalues after principal component analysis. (DOCX $23 \mathrm{~kb}$ )

\section{Abbreviations}

BMI: Body mass index; Cl: Confidence interval; DR: Dietary recall; HDLC: High-density lipoprotein cholesterol; KNHANES: Korea National Health and Nutrition Examination Survey; LDL-C: Low density lipoprotein cholesterol; OR: Odds ratios; TAC: Total antioxidant capacity; TG: Triglycerides; VCE: Vitamin C equivalents; VLDL: Very low-density lipoproteins

\section{Acknowledgements}

Not applicable.

\section{Authors' contributions}

S-AK performed statistical analysis, and drafted and revised the manuscript. $\mathrm{HJ}$ conceptualized and designed the study, and reviewed the manuscript. SS contributed to the interpretation of the data and critical revision of the manuscript. All authors read and approved the final manuscript.

\section{Funding}

This research was supported by Basic Science Research Program through the National Research Foundation of Korea (NRF) funded by the Ministry of Science and ICT (NRF-2018R1A2B6007070). 


\section{Availability of data and materials}

The dataset of the KNHANES is accessible through the official website of the KNHANES (http://knhanes.cdc.go.kr).

\section{Ethics approval and consent to participate}

The present study was conducted according to the guidelines laid down in the Declaration of Helsinki. All procedures for the Korea National Health and Nutrition Examination Survey were approved by the Korea Centers for Disease Control and Prevention Institutional Review Board (IRB No: 200702CON-04-P, 2008-04EXP-01-C, 2009-01 CON-03-2C, 2010-02CON-21-C, 201102CON-06-C, and 2012-01EXP-01-2C), and all participants provided written informed consent.

\section{Consent for publication}

Not applicable.

\section{Competing interests}

The authors declare that they have no competing interests.

\section{Author details}

'Department of Food and Nutrition, Chung-Ang University, Gyeonggi-do 17546, Korea. ${ }^{2}$ Institute of Health and Environment, Seoul National University, Seoul 08826, Korea. ${ }^{3}$ Graduate School of Public Health, Seoul National University, Seoul 08826, Korea.

Received: 18 February 2019 Accepted: 12 June 2019

Published online: 13 July 2019

\section{References}

1. Panel ED, Grundy SM. An international atherosclerosis society position paper: global recommendations for the management of dyslipidemia. J Clin Lipidol. 2013;7:561-5.

2. Varady KA, Jones PJ. Combination diet and exercise interventions for the treatment of dyslipidemia: an effective preliminary strategy to lower cholesterol levels? J Nutr. 2005;135:1829-35.

3. Musunuru K. Atherogenic dyslipidemia: cardiovascular risk and dietary intervention. Lipids. 2010:45:907-14

4. Ministry of Health and Welfare \& Korea Centers for Disease Control and Prevention. Korea Health Statistics 2012: Korea National Health and Nutrition Examination Survey (KNHANES V-3). Cheongwon: Korea Centers for Disease Control and Prevention; 2013.

5. Ministry of Health and Welfare \& Korea Centers for Disease Control and Prevention. Korea Health Statistics 2010: Korea National Health and Nutrition Examination Survey (KNHANES V-1). Cheongwon: Korea Centers for Disease Control and Prevention; 2011.

6. Huxley RR, Barzi F, Lam TH, Czernichow S, Fang X, Welborn T, Shaw J, Ueshima H, Zimmet P, Jee SH, Patel JV, Caterson I, Perkovic V, Woodward M. Asia Pacific cohort studies collaboration and the obesity in Asia collaboration. Isolated low levels of high-density lipoprotein cholesterol are associated with an increased risk of coronary heart disease. Circulation. 2011;124:2056-64.

7. Yu-Poth S, Z Zhao G, Etherton T, Naglak M, Jonnalagadda S, Kris-Etherton PM. Effects of the National Cholesterol Education Program's step I and step II dietary intervention programs on cardiovascular disease risk factors: a meta-analysis. Am J Clin Nutr 1999; 69: 632-646.

8. Nakanishi N, Nakamura K, Suzuki K, Tatara K. Lifestyle and the development of dyslipidemia: a 4-year follow-up study of middle-aged Japanese male office workers. Environ Health Prev Med. 1999;4:140.

9. Kris-Etherton PM, Binkoski AE, Zhao G, Coval SM, Clemmer KF, Hecker HD, Jacques $H$, Etherton TD. Dietary fat: assessing the evidence in support of a moderate-fat diet; the benchmark based on lipoprotein metabolism. Proc Nutr Soc. 2002;61:287-98.

10. Clarke R, Frost C, Collins R, Appleby P, Peto R. Dietary lipids and blood cholesterol: quantitative meta-analysis of metabolic ward studies. Bmj. 1997;314:112.

11. Jenkins D, Wolever T, Rao AV, Hegele RA, Mitchell SJ, Ransom T, Boctor DL, Spadafora PJ, Jenkins AL, Mehling C, Relle LK, Connelly PW, Story JA, Furumoto EJ, Corey P, Wursch P. Effect on blood lipids of very high intakes of fiber in diets low in saturated fat and cholesterol. N Engl J Med. 1993; 329:21-6.

12. Fornés NS, Martins IS, Hernan M, Velásquez-Meléndez G, Ascherio A. Food frequency consumption and lipoproteins serum levels in the population of an urban area, Brazil. Revista de saude publica. 2000;34:380-7.
13. Djoussé L, Arnett DK, Coon H, Province MA, Moore LL, Ellison RC. Fruit and vegetable consumption and LDL cholesterol: the national heart, lung, and blood institute family heart study. Am J Clin Nutr. 2004;79:213-7.

14. Wang H, Cao G, Prior RL. Total antioxidant capacity of fruits. J Agric Food Chem. 1996;44:701-5.

15. Ames BN, Shigenaga MK, Hagen TM. Oxidants, antioxidants, and the degenerative diseases of aging. Proc Natl Acad Sci. 1993;90:7915-22.

16. Graf BA, Milbury PE, Blumberg JB. Flavonols, flavones, flavanones, and human health: epidemiological evidence. J Med Food. 2005;8:281-90.

17. Vinson JA, Su X, Zubik L, Bose P. Phenol antioxidant quantity and quality in foods: fruits. J Agric Food Chem. 2001;49:5315-21.

18. Gaziano JM, Hennekens $\mathrm{CH}$. Vitamin antioxidants and cardiovascular disease. Curr Opin Lipidol. 1992;3:291-4.

19. Byers T, Perry G. Dietary carotenes, vitamin C, and vitamin E as protective antioxidants in human cancers. Annu Rev Nutr. 1992;12:139-59.

20. Serafini M, Del Rio D. Understanding the association between dietary antioxidants, redox status and disease: is the total antioxidant capacity the right tool? Redox Rep. 2004;9:145-52.

21. Floegel A, Kim D-O, Chung S-J, Song WO, Fernandez ML, Bruno RS, Koo SI, Chun OK. Development and validation of an algorithm to establish a total antioxidant capacity database of the US diet. Int J Food Sci Nutr. 2010;61: 600-23.

22. Serafini M, Bellocco R, Wolk A, Ekström AM. Total antioxidant potential of fruit and vegetables and risk of gastric cancer. Gastroenterology. 2002;123: 985-91.

23. Franzini $L$, Ardigò D, Valtueña S, Pellegrini N, Del Rio D, Bianchi MA, Scazzina F, Piatti PM, Brighenti F, Zavaroni I. Food selection based on high total antioxidant capacity improves endothelial function in a low cardiovascular risk population. Nutr Metab Cardiovasc Dis. 2012;22:50-7.

24. Pandey KB, Rizvi SI. Plant polyphenols as dietary antioxidants in human health and disease. Oxidative Med Cell Longev. 2009;2:270-8.

25. Hu FB. Dietary pattern analysis: a new direction in nutritional epidemiology. Curr Opin Lipidol. 2002;13:3-9.

26. Wie G-A, Cho Y-A, Kang H-h, Ryu KA, Yoo M-K, Kim J, Shin S, Chun OK, Joung $\mathrm{H}$. Identification of major dietary patterns in Korean adults and their association with cancer risk in the Cancer screening examination cohort. Eur J Clin Nutr. 2017;71:1223-9.

27. International Obesity Task Force \& World Health Organization. The AsianPacific perspective: redefining obesity and its treatment. Melbourne: Health Communications Australia; 2000.

28. Committee for the Korean Guidelines for the Management of Dyslipidemia. 2015 Korean guidelines for the management of dyslipidemia: executive summary. Korean Circ J. 2016;46(3):275-306.

29. Kim SH, Kim TH, Hwang HJ. The relationship of physical activity (PA) and walking with sarcopenia in Korean males aged 60 years and older using the fourth Korean National Health and nutrition examination survey (KNHANES IV-2, 3), 2008-2009. Arch Gerontol Geriatr. 2013;56(3):472-7.

30. Jun $\mathrm{S}$, Chun OK, Joung $\mathrm{H}$. Estimation of dietary total antioxidant capacity of Korean adults. Eur J Nutr. 2018:57:1615-25.

31. Kim J, Jo I, Joung H. A rice-based traditional dietary pattern is associated with obesity in Korean adults. J Acad Nutr Diet. 2012;112:246-53.

32. Hong S, Song YJ, Lee KH, Lee HS, Lee M, Jee SH, Joung H. A fruit and dairy dietary pattern is associated with a reduced risk of metabolic syndrome. Metab Clin Exp. 2012;61:883-90.

33. Kim SH, Kim MS, Lee MS, Park YS, Lee HJ, Kang S, Lee HS, Lee KE, Yang HJ, Kim MJ, Lee YE, Kwon DY. Korean diet: characteristics and historical background. J Ethnic Foods. 2016;3(1):26-31.

34. Patra JK, Das G, Paramithiotis S, Shin HS. Kimchi and other widely consumed traditional fermented foods of Korea: a review. Front Microbiol. 2016;7:1-15.

35. Kil JH, Jung KO, Lee HS, Hwang IK, Kim YJ, Park KY. Effects of kimchi on stomach and colon health of helicobacter pylori-infected volunteers. Prev Nutr Food Sci. 2004;9(2):161-6.

36. Kim JH, Ryu JD, Lee HG, Park JH, Moon GS, Cheigh HS, Song YO. The effect of kimchi on production of free radicals and anti-oxidative enzyme activities in the brain of SAM. J Korean Soc Food Sci Nutr. 2002;31(1):117-23.

37. Kim M, Kwon M, Song Y, Lee $E$, Youn H, Song Y. The effects of kimchi on hematological and immunological parameters in vivo and in vitro. J Korean Soc Food Sci Nutr. 1997;26:1208-14.

38. Knuiman JT, West CE, Katan MB, Hautvast JG. Total cholesterol and high density lipoprotein cholesterol levels in populations differing in fat and carbohydrate intake. Arterioscler Thromb Vasc Biol. 1987;7:612-9. 
39. Choi H, Song SJ, Kim J, Chung J, Yoon J, Paik H-Y, Song YJ. High carbohydrate intake was inversely associated with high-density lipoprotein cholesterol among Korean adults. Nutr Res. 2012;32:100-6.

40. Murakami K, Sasaki S, Takahashi Y, Okubo H, Hosoi Y, Horiguchi H, Oguma E, Kayama F. Dietary glycemic index and load in relation to metabolic risk factors in Japanese female farmers with traditional dietary habits. Am J Clin Nutr. 2006;83:1161-9.

41. Erkkilä AT, Herrington DM, Mozaffarian D, Lichtenstein AH. Cereal fiber and whole-grain intake are associated with reduced progression of coronaryartery atherosclerosis in postmenopausal women with coronary artery disease. Am Heart J. 2005;150(1):94-101.

42. Song S, Paik HY, Park M, Song Y. Dyslipidemia patterns are differentially associated with dietary factors. Clin Nutr. 2016;35:885-91.

43. Williams L. Third report of the National Cholesterol Education Program (NCEP) expert panel on detection, evaluation, and treatment of high blood cholesterol in adults (adult treatment Panel III) final report. Circulation. 2002:106:3143.

44. Obarzanek E, Kimm SYS, Barton BA, Horn RV, Kwiterovich PO, Simons-Morton DG, Hunsberger SA, Lasser NL, Robson AM, Franklin FA, Lauer RM, Stevens VJ, Friedman LA, Dorgan JF, Greenlick MR. On behalf of the DISC collaborative research group. Long-term safety and efficacy of a cholesterol-lowering diet in children with elevated low-density lipoprotein cholesterol: seven-year results of the dietary intervention study in children (DISC). Pediatrics. 2001;107:256-64.

45. Howell WH, McNamara DJ, Tosca MA, Smith BT, Gaines JA. Plasma lipid and lipoprotein responses to dietary fat and cholesterol: a meta-analysis. Am J Clin Nutr. 1997;65:1747-64.

46. Crouse JR, Morgan T, Terry JG, Ellis J, Vitolins M, Burke GL. A randomized trial comparing the effect of casein with that of soy protein containing varying amounts of isoflavones on plasma concentrations of lipids and lipoproteins. Arch Intern Med. 1999;159:2070-6.

47. Sloth B, Krog-Mikkelsen I, Flint A, Tetens I, Björck I, Vinoy S, Elmståhl H, Astrup A, Lang $V$, Raben A. No difference in body weight decrease between a low-glycemicindex and a high-glycemic-index diet but reduced LDL cholesterol after 10-wk ad libitum intake of the low-glycemic-index diet. Am J Clin Nutr. 2004;80:337-47.

48. Von Schacky C. Prophylaxis of atherosclerosis with marine omega-3 fatty acids: a comprehensive strategy. Ann Intern Med. 1987;107:890-9.

49. von Schacky C. A review of omega-3 ethyl esters for cardiovascular prevention and treatment of increased blood triglyceride levels. Vasc Health Risk Manag. 2006;2:251-62.

50. Takahashi K, Kamada C, Yoshimura H, Okumura R, limuro S, Ohashi Y, Araki A, Umegaki H, Sakurai T, Yoshimura Y, Ito H. Effects of total and green vegetable intakes on glycated hemoglobin A1c and triglycerides in elderly patients with type 2 diabetes mellitus: the Japanese elderly intervention trial. Geriatr Gerontol Int. 2012;12:50-8.

51. Sabaté J, Oda K, Ros E. Nut consumption and blood lipid levels: a pooled analysis of 25 intervention trials. Arch Intern Med. 2010;170:821-7.

52. Brighenti F, Valtueña S, Pellegrini N, Ardigò D, Del Rio D, Salvatore S, Piatti PM, Serafini M, Zavaroni I. Total antioxidant capacity of the diet is inversely and independently related to plasma concentration of high-sensitivity Creactive protein in adult Italian subjects. Br J Nutr. 2005;93:619-25.

53. Serafini $M$, Jakszyn $P$, Luján-Barroso $L$, Agudo $A$, Bueno-de-Mesquita $H$, van Duijnhoven $F$, Jenab M, Navarro C, Palli D, Boeing $H$, Wallström P, Regnér $S$, Numans ME, Carneiro F, Boutron-Ruault MC, Clavel-Chapelon F, Morois S, Grioni S, Panico S, Tumino R, Sacerdote C, Quirós JR, Molina-Montes E, Castaño JMH, Barricarte A, Amiano P, Khaw KT, Wareham N, Allen NE, Key TJ, Jeurnink SM, Peeters P, Bamia C, Valanou E, Trichopoulou A, Kaaks R, Lukanova A, Bergmann MM, Lindkvist B, Stenling R, Johansson I, Dahm CC, Overvad K, Jensen M, Olsen A, Tjonneland A, Lund E, Rinaldi S, Michaud D, Mouw T, Riboli E, González CA. Dietary total antioxidant capacity and gastric cancer risk in the European prospective investigation into cancer and nutrition study. Int J Cancer. 2012;131:E544-54

54. Vecchia C, Decarli A, Serafini M, Parpinel M, Bellocco R, Galeone C, Bosetti C, Zucchetto A, Polesel J, Lagiou P, Negri E, Rossi M. Dietary total antioxidant capacity and colorectal cancer: a large case-control study in Italy. Int J Cancer. 2013;133:1447-51.

55. Martinez ME, Marshall JR, Sechrest L. Invited commentary: factor analysis and the search for objectivity. Am J Epidemiol. 1998;148:17-9.

\section{Publisher's Note}

Springer Nature remains neutral with regard to jurisdictional claims in published maps and institutional affiliations.

Ready to submit your research? Choose BMC and benefit from:
- fast, convenient online submission
- thorough peer review by experienced researchers in your field
- rapid publication on acceptance
- support for research data, including large and complex data types
- gold Open Access which fosters wider collaboration and increased citations
- maximum visibility for your research: over 100M website views per year
At BMC, research is always in progress.
Learn more biomedcentral.com/submissions

